\title{
MELHORIAS NAS PROPRIEDADES QUÍMICAS DE UM SOLO SALINO-SÓDICO E RENDIMENTO DE ARROZ, SOB DIFERENTES TRATAMENTOS ${ }^{1}$
}

\author{
Everaldo Mariano Gomes ${ }^{2}$, Hans Raj Gheyi ${ }^{3}$ \& Ênio Farias de França e Silva ${ }^{4}$
}

\begin{abstract}
RESUMO
Instalou-se um experimento num solo salino-sódico no Perímetro Irrigado de São Gonçalo, com o objetivo de se avaliar o efeito de diferentes produtos condicionadores nas propriedades químicas do solo e seus reflexos nos componentes de produção e rendimento de grãos na cultura de arroz irrigado (Oryza sativa L.). O delineamento experimental foi inteiramente casualizado, com cinco tratamentos e cinco repetições. Os tratamentos estudados foram: gesso (20 Mg ha-1); casca de arroz (15 Mg ha-1); testemunha; vinhaça $\left(40 \mathrm{~m}^{3} \mathrm{ha}^{-1}\right)$ e esterco de curral $\left(40 \mathrm{Mg} \mathrm{ha}^{-1}\right)$. Após aplicação dos tratamentos, $\mathrm{o}$ solo foi lixiviado durante 40 dias, mantendo uma lâmina de $8 \mathrm{~cm}$ de água nas parcelas. Os tratamentos mostraram efeitos positivos nas propriedades químicas do solo (percentagem de sódio trocável, condutividade elétrica do extrato de saturação e pH da pasta saturada) sendo que o esterco de curral e gesso proporcionaram apreciáveis decréscimos em comparação aos outros tratamentos; entretanto, os produtos utilizados não mostraram efeitos significativos no número de panículas, peso de panículas e rendimento do arroz.
\end{abstract}

Palavras-chave: salinidade, salino-sódico, condicionadores, Oryza sativa L.

\section{IMPROVEMENT IN CHEMICAL PROPERTIES OF A SALINE-SODIC SOIL AND RICE YIELD UNDER DIFFERENT TREATMENTS}

\begin{abstract}
An experiment was installed in a saline-sodic soil of the Irrigated Perimeter of São Gonçalo, with the objective of evaluating the effect of different amendments in the chemical properties of soil and its posterior reflexes in the components of production and grain yield of irrigated rice (Oryza sativa L.). The experiment consisted of five treatments with five replications in a completely randomized design. The treatments studied were: gypsum $\left(20 \mathrm{Mg} \mathrm{ha}^{-1}\right)$; rice husk $\left(15 \mathrm{Mg} \mathrm{ha}^{-1}\right)$; control; stillage $\left(40 \mathrm{~m}^{3} \mathrm{ha}^{-1}\right)$ and farmyard manure ( $40 \mathrm{Mg} \mathrm{ha}^{-1}$ ). After incorporation of amendments, the soil was leached for 40 days, keeping an $8 \mathrm{~cm}$ depth of water in the plots. The treatments showed positive effects in the chemical properties of the soil (exchangeable sodium percentage, electrical conductivity of saturation extract and $\mathrm{pH}$ of saturation paste), and the treatments with farmyard manure and gypsum caused an appreciable decrease in comparison to the other treatments; however the products used did not show significant effects on the number of panicles, weight of panicles and rice yields.
\end{abstract}

Key words: salinity, saline-sodic, amendments, Oryza sativa $L$.

Recebido em 26/01/2000, Protocolo 011/00

${ }^{1}$ Parte da Dissertação de Mestrado do primeiro autor, realizada no Departamento de Engenharia Agrícola DEAg/UFPB

${ }^{2}$ M.Sc. Engenharia Agrícola, Professor da Escola Agrotécnica Federal, Rua Tancredo Neves S/N, Jardim Sorrilândia, CP 49, CEP 58805 - 970, Sousa, PB. Fone: (0xx83) 522 2727, Fax: (0xx83) 5222728

${ }^{3}$ Doutor, Professor DEAg/UFPB, Rua Aprígio Veloso 882, Bodocongó, CP 10056, CEP 58109 - 970, Campina Grande, PB. Fone: (0xx83) 310 1056, Fax: (0xx83) 310 1185.E-mail: hans@deag.ufpb.br

${ }^{4}$ M.Sc. Engenharia Agrícola, Doutorando, ESALQ/USP-DER. Av. Pádua Dias 11, Piracicaba, SP, CEP 13418 - 900. Fone: (0xx19) 429 4217, Fax: (0xx19) 433 0934. E-mail: effsilva@carpa.ciagri.usp.br 


\section{INTRODUÇÃO}

A origem dos solos salinos e sódicos é um fenômeno observado particularmente sob condições de aridez. As altas taxas de evaporação e baixa precipitação, associadas às características do material de origem e às condições geomorfológicas e hidrológicas, condicionam a formação de solos com teores elevados de sais solúveis e sódio trocável, que comprometem o crescimento e o desenvolvimento das culturas (Whitemore, 1975).

Um dos objetivos primordiais da agricultura é satisfazer as necessidades alimentícias da humanidade, que aumentam a medida em que a população cresce. Segundo UN (1991) a população mundial é, atualmente, de cerca de 5,5 bilhões e há perspectiva de atingir 8,5 bilhões no ano 2025. Neste contexto, a incorporação de áreas afetadas por sais no processo produtivo de alimentos é de fundamental importância, do ponto de vista social e econômico. De acordo com estimativas de Kovda \& Szabolcs (1979) cerca de 954 milhões de hectares de terras no mundo estão com problemas de salinidade. Chapman (1975) avaliou a salinidade neste particular e destaca que, nos Estados Unidos, o problema ocorre principalmente na bacia do Great Salt Lake, nos vales da Califórnia, nas bacias de drenagem do Colorado e Rio Grande, além de em partes das bacias do Colúmbia e do Missouri. Na Europa, acontece em extensas áreas da Hungria e Romênia, enquanto no continente africano o Egito se destaca por apresentar cerca de 121,5 mil hectares salinizados, devido à irrigação ao longo do Rio Nilo. Na América do Sul, além do Brasil, destacam-se Argentina e Paraguai.

No tocante ao Brasil, existem cerca de 4,5 milhões de hectares salinizados (Kovda \& Szabolcs, 1979) localizados principalmente na região Nordeste, em áreas pertencentes ao polígono das secas, onde se concentram os perímetros irrigados. Segundo Goes (1978) aproximadamente 25\% das áreas irrigadas nos perímetros irrigados do Nordeste apresentam problemas de salinidade. Cordeiro et al. (1988) mostram que 24\% da área do projeto de irrigação de São Gonçalo, PB, estão afetados por sais, isto sem se considerar as áreas já abandonadas em virtude de altos teores de sais e/ou sódio trocável. Conforme DNOCS (1991) a área afetada por salinidade nos diversos perímetros irrigados varia de 3 a 29,4\% da superfície agrícola útil e ao nível de Nordeste, a percentagem média é de 7,8\% que corresponde a 2000 ha

De acordo com FAO/UNESCO (1973) a utilização de condicionadores, como gesso, ácido sulfúrico, enxofre ou aplicação de grandes quantidades de matéria orgânica, é solução para solos com problemas de sodicidade. Trabalhos realizados pelo Departamento de Engenharia Agrícola na Universidade Federal da Paraíba (Azevedo, 1983; Leite, 1990; Gheyi, 1993; Gheyi et al., 1995 e Silva, 1997) mostram resultados satisfatórios com a utilização desses produtos. Almeida (1994) trabalhando com a vinhaça, conseguiu excelentes resultados em solo salino-sódico. Esses trabalhos indicam a possibilidade de recuperação e utilização desses solos, com quantidades adequadas de resíduos orgânicos (esterco de curral, vinhaça) ou condicionadores químicos (gesso, ácido sulfúrico) para cultivo de arroz no primeiro ano, fato este com que, em decorrência da disponibilidade dos produtos na região e tradição no cultivo do arroz, justifica-se a utilização dos mesmos na recuperação de solos afetados por sais.
O objetivo deste trabalho foi avaliar o efeito dos diversos produtos de procedência orgânica, como esterco de curral, vinhaça e casca de arroz, nas propriedades químicas de um solo salino-sódico, além de estudar seus reflexos sobre os componentes de produção e rendimento de arroz irrigado e compará-los com a aplicação do gesso e a testemunha.

\section{MATERIAL E MÉTODOS}

O presente trabalho foi desenvolvido no período de novembro de 1996 a abril de 1997, na Estação Experimental da EMBRAPA Algodão, localizada no Perímetro Irrigado de São Gonçalo, Sousa, PB, no Vale do Rio Piranhas; a altitude média do perímetro é de $235 \mathrm{~m}$ acima do nível do mar e apresenta as seguintes coordenadas geográficas: latitude sul $6^{\circ} 50^{\prime} \mathrm{e}$ longitude $38^{\circ} 19^{\prime}$ a oeste do meridiano de Greenwich. A estação experimental situa-se numa região de clima semi-árido quente, do tipo Bsh da classificação de Köppen, ou seja, a evaporação é superior à precipitação, com período chuvoso coincidindo com os meses de janeiro a maio; a temperatura média anual é de $27{ }^{\circ} \mathrm{C}$, com máxima de $38{ }^{\circ} \mathrm{C}$ e umidade relativa do ar $64 \%$ (DNOCS, 1997). Um estudo diagnóstico da salinidade realizado por Silva et al. (1997) mostrou que a área em questão apresenta problema de caráter salino-sódico com amplitudes de condutividade elétrica do extrato de saturação e percentagem de sódio trocável entre 3,9 e 10,7 dS m $\mathrm{m}^{-1}$ e 7,6 e 45,4\%, respectivamente.

A Figura 1 mostra o aspecto geral da área onde foi instalado o experimento, obedecendo a um delineamento inteiramente casualizado, com 5 tratamentos e 5 repetições, de 10 × 10 m, perfazendo uma área experimental de $2500 \mathrm{~m}^{2}$, tendo como área útil $1600 \mathrm{~m}^{2}$ (64 m², 8 x 8m centrais, em cada repetição). Os tratamentos foram os seguintes: $\mathrm{T}_{1}$ - Gesso $\left(20 \mathrm{Mg} \mathrm{ha}^{-1}\right)$; $\mathrm{T}_{2}$ - Casca de arroz (15 $\left.\mathrm{Mg} \mathrm{ha}^{-1}\right) ; \mathrm{T}_{3}$ - Testemunha; $\mathrm{T}_{4}$ - Vinhaça $\left(40 \mathrm{~m}^{3} \mathrm{ha}^{-1}\right)$ e $\mathrm{T}_{5}$ - Esterco de curral $\left(40 \mathrm{Mg} \mathrm{ha}^{-1}\right)$. A quantidade dos diversos produtos, foi baseada em trabalhos anteriores (Azevedo, 1983; Leite, 1990 e Almeida, 1994) e/ou levando-se em consideração os aspectos de disponibilidade do produto na região.

As operações de implantação do experimento compreenderam o nivelamento do terreno, uma aração na profundidade de $30 \mathrm{~cm}$ e duas gradagens niveladoras, visando facilitar as irrigações e manter a uniformidade da lâmina de água. Também, foram providenciados a limpeza e o aprofundamento dos drenos coletores, a aproximadamente 1,2 m, situados a uma distância de $50 \mathrm{~m}$ no sentido norte e $75 \mathrm{~m}$ no sentido oeste. Em torno das

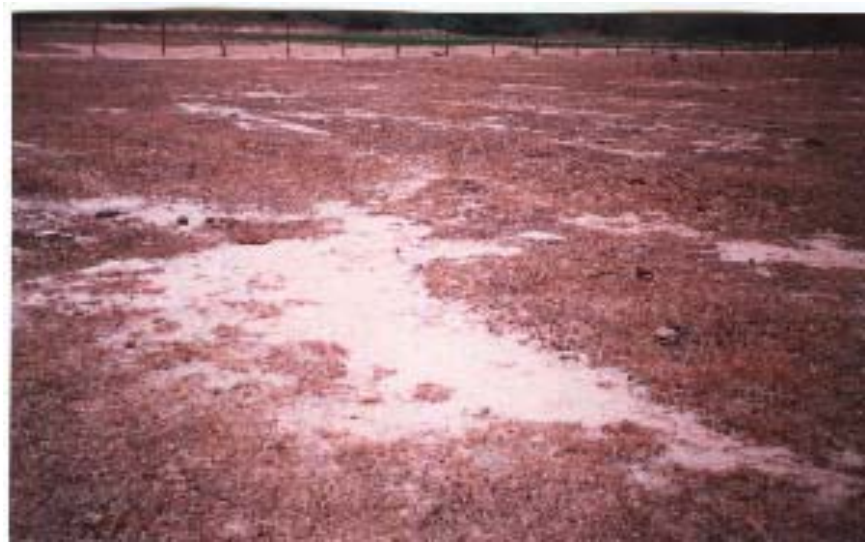

Figura 1. Aspectos gerais do solo da área experimental 
parcelas construíram-se diques de contenção de água, para a aplicação da lâmina de água; a incorporação dos produtos gesso, esterco de curral e casca de arroz foi manual, tendo-se o cuidado de incorporá-los uniformemente no interior das parcelas, enquanto na parcela destinada ao tratamento com vinhaça colocou-se, inicialmente, uma lâmina de água de aproximadamente $5 \mathrm{~cm}$ e, em seguida, fez-se a aplicação do produto. Posteriormente, provocou-se turbulência na mistura, a fim de possibilitar uma uniformização melhor da mesma. Durante 40 dias, fez-se a lavagem do solo, mantendo uma lâmina de água de $8 \mathrm{~cm}$ na sua superfície (Figura 2).

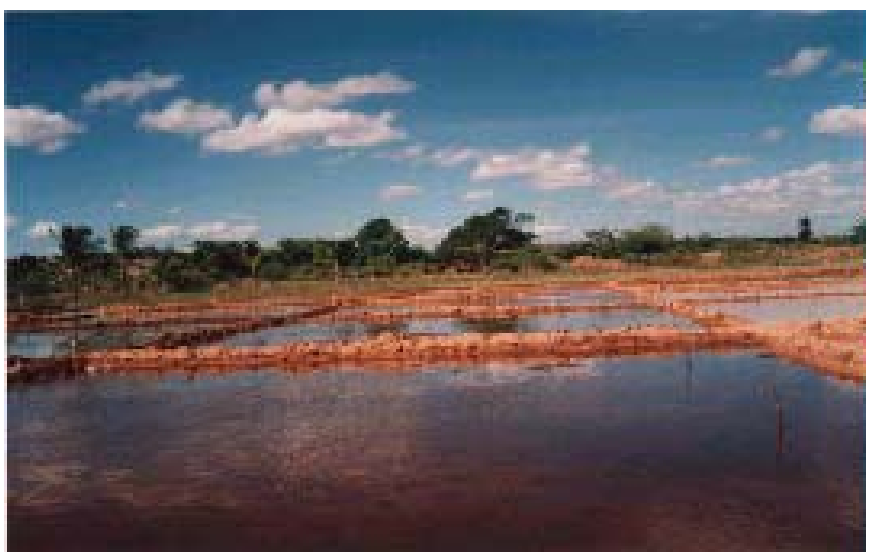

Figura 2. Lavagem do solo

Simultaneamente e em um canteiro de $50 \mathrm{~m}^{2}$ plantaram-se, a lanço, $2 \mathrm{~kg}$ de semente de arroz, da variedade Diamante. As mudas obtidas foram utilizadas para transplantio quando estavam com 40 dias, adotando-se o espaçamento de $25 \mathrm{~cm}$ entre linhas e $10 \mathrm{~cm}$ entre covas, deixando-se 3 mudas por cova. No período de cultivo de arroz manteve-se sempre uma lâmina de água entre 2,5 e $5 \mathrm{~cm}$ nas parcelas. Conforme praticas e recomendações para região foram realizadas adubações de cobertura com sulfato de amônio, utilizando-se a dosagem equivalente a $100 \mathrm{~kg} \mathrm{ha}^{-1}$ de N, parceladas em duas aplicações, metade no início do perfilhamento e o restante no início da fase de emborrachamento.

Em cada unidade experimental foram coletadas amostras de solo em 3 pontos eqüidistantes, em três épocas distintas (antes da incorporação dos condicionadores, após 40 dias de lavagem e após a colheita do arroz) procurando-se retirar as amostras, sempre no mesmo local, nas camadas de 0 - 20, 20 - 40 e 40 - 60 $\mathrm{cm}$ de profundidade. As amostras foram analisadas em laboratório quanto à condutividade elétrica do extrato de saturação (CEes), $\mathrm{pH}$ da pasta saturada $\left(\mathrm{pH}_{\mathrm{ps}}\right)$, percentagem de sódio trocável (PST) a partir da análise dos cátions trocáveis, de acordo com as metodologias recomendadas pela EMBRAPA (1997). Os reflexos dos tratamentos sobre os componentes de produção (número de panículas por metro linear - NP, comprimento da panícula - $\mathrm{CP}$, número de ramificações por panícula - NR, peso da panícula - PP, número de grãos cheios por panícula - NG, densidade da panícula - DP, peso de 100 grãos $-\mathrm{P}_{100}$ ) e rendimento, foram avaliados mediante análise de variância com teste de $\mathrm{F}$ seguido do contraste das médias pelo teste de Tukey, sendo que nas variáveis número de panículas, peso de panícula e número de grãos cheios, a análise estatística foi realizada após a transformação em raiz quadrada, enquanto os dados de rendimento foram convertidos em ln (logaritmo neperiano). Além do efeito entre os tratamentos, estudou-se o efeito dos seguintes contrastes: controle $\left(\mathrm{T}_{3}\right)$ versus outros tratamentos $\left(\mathrm{T}_{1}+\mathrm{T}_{2}+\mathrm{T}_{4}+\mathrm{T}_{5}\right)$, gesso $\left(\mathrm{T}_{1}\right)$ versus tratamentos orgânicos $\left(\mathrm{T}_{2}+\mathrm{T}_{4}+\mathrm{T}_{5}\right)$, vinhaça $\left(\mathrm{T}_{4}\right)$ versus casca de arroz + esterco de curral $\left(\mathrm{T}_{2}+\mathrm{T}_{5}\right)$ e casca de arroz $\left(\mathrm{T}_{2}\right)$ versus esterco de curral $\left(\mathrm{T}_{5}\right)$.

\section{RESULTADOS E DISCUSSÃO}

\section{Efeito da aplicação dos condicionadores nas propriedades químicas do solo}

Propriedades do solo antes da aplicação dos condicionadores: Os resultados das análises do solo, no que diz respeito às características para diagnóstico dos problemas de salinidade (PST, CEes, pHps) no início do experimento, apresentaram grande variabilidade espacial, tanto horizontal como em profundidade (Fig. 3) evidenciando, conforme Richards (1954) caráter salino-sódico do solo, $\left(\mathrm{CEes}>4 \mathrm{dS} \mathrm{m}^{-1}, \mathrm{PST}>15 \mathrm{e} \mathrm{pH}_{\mathrm{ps}}\right.$ $>8,2)$ até a profundidade de $60 \mathrm{~cm}$. Os valores encontrados estão em conformidade com os obtidos por Silva et al. (1997). Oliveira et al. (1999) avaliando as propriedades químicas do solo na mesma área experimental constataram, também, grande amplitude de variação entre os parâmetros químicos do solo, caracterizando a heterogeneidade da área, fato comum em solos aluvionais, sobretudo naqueles afetados por sais.

Propriedades do solo após a lavagem: Analisando-se a Figura 3 , observa-se que, nas profundidades estudadas após a lavagem, ocorreram reduções nos valores da PST do solo independente dos tratamentos, exceto para testemunha na profundidade de $40-60 \mathrm{~cm}$, que indicou um aumento da PST, de $48 \%$ para $57 \%$. As reduções foram mais relevantes nas camadas de 0 - 20 e 20 - $40 \mathrm{~cm}$ de profundidade do solo, com destaque para a camada de $0-20 \mathrm{~cm}$, onde ocorreram diminuições da PST de 48,5\% para 14\%, no tratamento com esterco de curral, de $46 \%$ para $29 \%$ para o tratamento com casca de arroz e de $25 \%$ para $17,7 \%$ para com o gesso. Os condicionadores orgânicos (esterco de curral, casca de arroz e vinhaça) reduziram a PST, possivelmente devido à liberação de $\mathrm{CO}_{2}$ e ácidos orgânicos, durante a decomposição anaeróbica da matéria orgânica quando submetida às condições de lavagem, além de atuarem como fontes de cálcio e magnésio mostrando, assim, a possibilidade do uso desses produtos na recuperação de solos salino-sódicos. De maneira geral, esses resultados estão de acordo com os obtidos por Abrol \& Bhumbla (1979), Leite (1990) e Silva (1997). Observa-se que as parcelas do tratamento com esterco de curral, apesar de apresentarem valor inicial de PST mais elevado em relação às parcelas tratadas com gesso, após a lavagem, nas profundidades de 0 - 20, 20 - 40 e 40 - $60 \mathrm{~cm}$, apresentaram valores médios de PST, de 14, 30 e $35 \%$, respectivamente, praticamente igual aos de gesso $(17,7$; 28 e 42,8\%). Gheyi et al. (1995) trabalhando no Perímetro Irrigado de Sumé, também constataram que solos salinos-sódicos são 

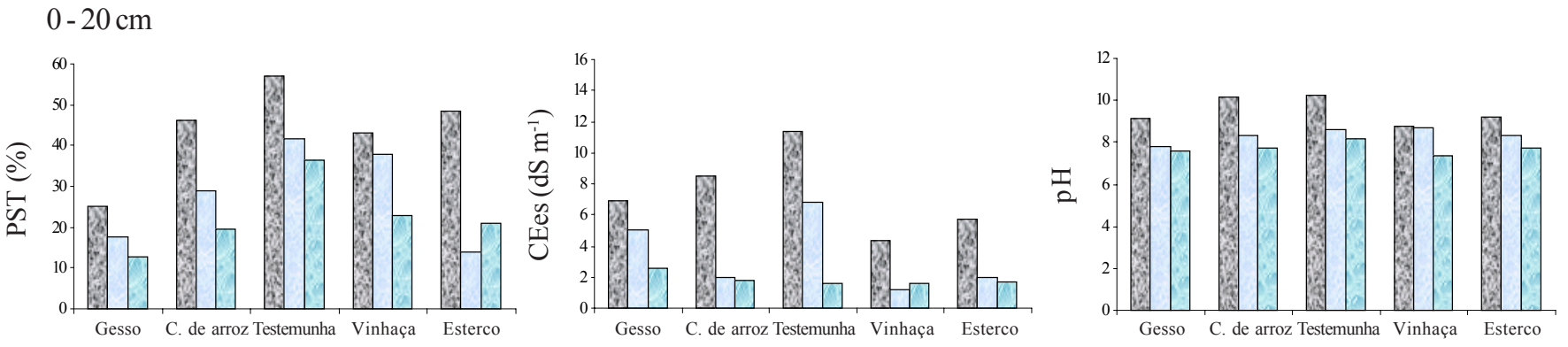

$20-40 \mathrm{~cm}$
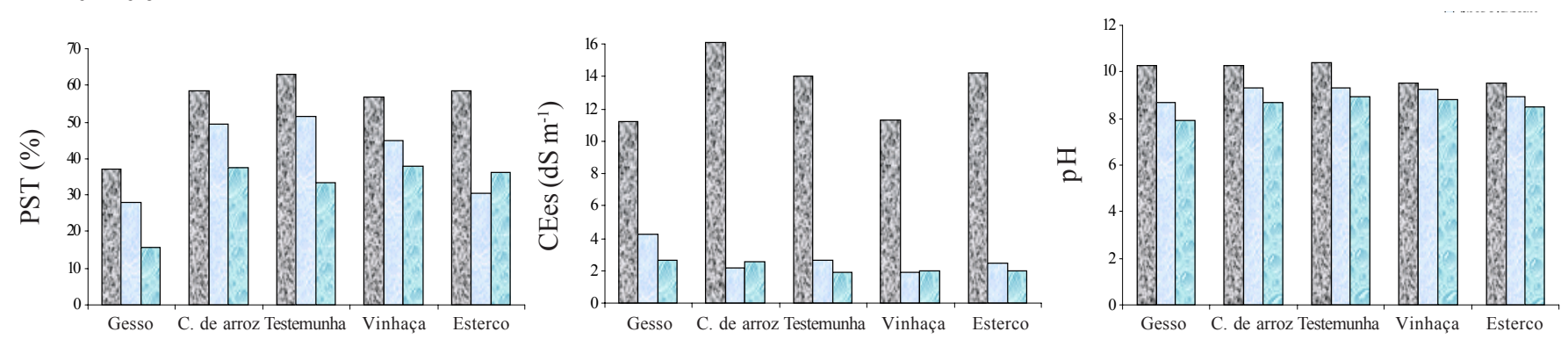

$40-60 \mathrm{~cm}$

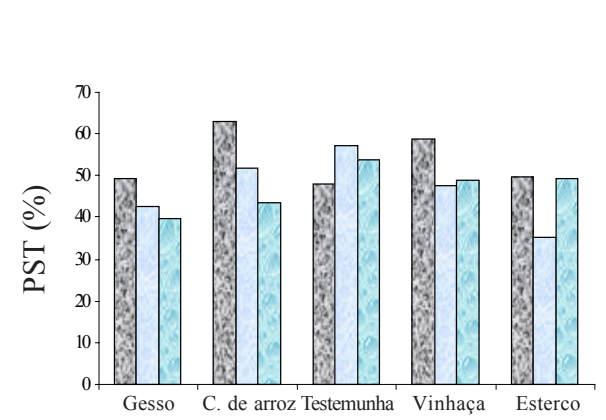

Tratamentos

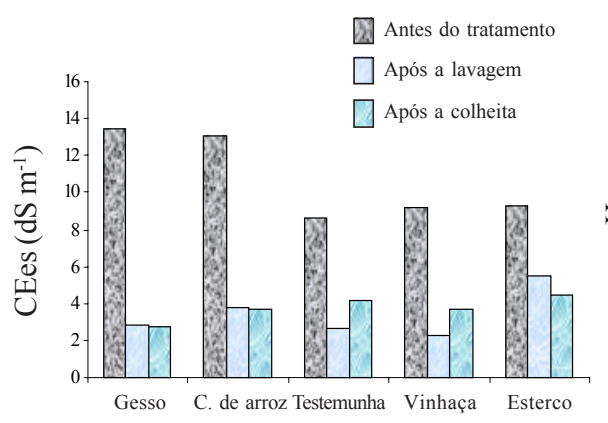

Tratamentos

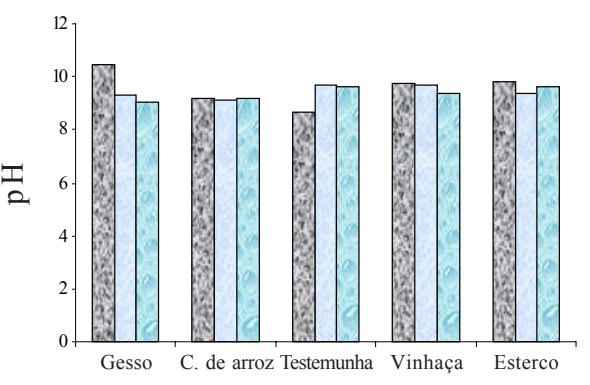

Tratamentos

Figura 3. Variação temporal da percentagem de sódio trocável (PST), condutividade elétrica do extrato de saturação (CEes) e pH da pasta saturada $\left(\mathrm{pH}_{\mathrm{ps}}\right)$ do perfil do solo

passíveis de recuperação apenas com lavagens, desde que os drenos circunvizinhos sejam aprofundados e mantidos limpos até a profundidade de $1,5 \mathrm{~m}$.

A concentração de sais, avaliada através dos valores de CEes (Fig. 3) foi reduzida com o tempo, em todos os tratamentos. Após 40 dias de lavagem houve decréscimo significativo da CEes, porém, a salinidade do solo da camada $0-20 \mathrm{~cm}$ de profundidade, nos tratamentos com gesso e testemunha, apresentando valores de 5 e $6,8 \mathrm{dS} \mathrm{m}^{-1}$, respectivamente, manteve-se acima da salinidade limiar para a cultura do arroz $\left(3,3 \mathrm{dS} \mathrm{m}^{-1}\right)$. A hipótese mais provável para explicar este fato é que o gesso é um composto químico de baixa solubilidade $\left(2,04 \mathrm{gL}^{-1}\right)$ e desta forma, as lâminas de água aplicadas provavelmente não foram suficientes para promover a dissolução e, conseqüentemente, percolação total do gesso, influenciando diretamente na concentração eletrolítica da solução do solo, resultados que se assemelham aos conseguidos por Holanda (1996) e Silva (1997). No tratamento testemunha a causa foi, provavelmente, a baixa permeabilidade do solo, sobretudo na profundidade além de $20 \mathrm{~cm}$, em virtude de alta PST do solo (> 50\%) (Fig. 3). Os baixos valores de CEes do tratamento com vinhaça, após a lavagem, foram devidos à sua alta concentração eletrolítica e ao alto teor de matéria orgânica iniciais, que proporcionaram melhoria na infiltração do solo tendo, em conseqüência, contribuído para maior eficiência na lixiviação dos sais solúveis. Ruiz et al. (1997) estudando o efeito da lavagem com vinhaça em solo salinosódico, também observaram este fato.

Os resultados de análises de solo também revelam que ocorreram modificações no $\mathrm{pH}$ da pasta de saturação, em todos os tratamentos utilizados (Figura 3). De modo geral, verificou-se que, após a lavagem, os valores de $\mathrm{pH}$ apresentaram uma ligeira tendência para decréscimo com o tempo; no entanto, verifica-se que as reduções foram menos acentuadas na camada mais profunda do solo $(40-60 \mathrm{~cm})$. O tratamento com gesso na camada superficial sobressaiu-se dos demais tratamentos tendo, na camada de 20 - $40 \mathrm{~cm}$ de profundidade, o valor do $\mathrm{pH}$ decrescido de 10,2 para 8,7; esta diminuição, foi em parte, conseqüência da substituição do sódio pelo cálcio no complexo sortivo e no deslocamento do sódio para camadas mais profundas (Moraes, 1973); como também pela precipitação do carbonato de cálcio devido a reação entre íons carbonatos e cálcio o comportamento do $\mathrm{pH}$ na profundidade de $40-60 \mathrm{~cm}$, após a lavagem, indica que praticamente, não houve alteração, exceto nas parcelas tratadas com gesso e esterco, as quais sofreram pequenos decréscimos, talvez em razão de melhoria da permeabilidade do solo abaixo da camada arável. 
Propriedades do solo após a colheita do arroz: Ao final do ensaio verificou-se que os tratamentos com esterco de curral, com casca de arroz e com vinhaça, apresentaram valores de PST semelhantes em todas as profundidades (Fig. 3). De maneira geral, as reduções da PST foram maiores nas profundidades de 0 - $20 \mathrm{~cm}$, intermediárias em 20 - $40 \mathrm{~cm}$ e menores na camada de $40-60 \mathrm{~cm}$ de profundidade. Observou-se, também, que em todos os tratamentos ocorreu diminuição da PST do solo após a colheita, com a exceção para o tratamento com esterco de curral, o qual sofreu ligeiro acréscimo nas profundidades de 20 - 40 e $40-60 \mathrm{~cm}$. A justificativa provável para esta variação pode estar associada à variabilidade espacial do solo, uma vez que as amostras de solo para análises, em diferentes épocas, não foram coletadas exatamente no mesmo local. Ao final do experimento, os menores valores da PST foram verificados no tratamento com gesso 12,$8 ; 15,6$ e $40 \%$ nas profundidades de 0 - 20; 20 - 40 e 40 - $60 \mathrm{~cm}$, respectivamente. A redução contínua da PST, mesmo após lavagem durante 40 dias, está associado à contribuição da cultura do arroz que, provavelmente, proporcionou aumento da permeabilidade do solo, fato explicado pela ação física de suas raízes, que facilitam o movimento da água (Chabra \& Abrol, 1977). Gupta et al. (1984) atribuíram tais reduções à solubilização de carbonatos presentes no solo, em virtude da liberação de $\mathrm{CO}_{2}$, o qual, após dissociar-se em $\mathrm{Ca}^{2+} \mathrm{e} \mathrm{CO}_{3}^{2-}$ aumenta a substituição do $\mathrm{Na}$ trocável no complexo sortivo (Santos \& Hernandez, 1997). Conforme McNeal et al. (1966) a assimilação de sódio pela cultura também pode ser um dos fatores para promover tal diminuição.

A redução da PST no tratamento testemunha, ao qual não foi aplicado qualquer condicionador, pode ser atribuída apenas à lavagem e/ou à presença, no solo, de carbonato de cálcio que, após a diluição, libera o cálcio para substituição do sódio o qual é mais fracamente retido no solo em relação ao cálcio podendo ser deslocado logo que haja portunidade.

A diminuição da CEes pode ser atribuída às práticas de preparo do solo (aração e gradagens) empregadas no início do experimento, que permitiram melhor infiltração da água no solo e, conseqüentemente, a diluição e eliminação dos sais existentes. $\mathrm{Na}$ camada de $0-20 \mathrm{~cm}$, a condutividade elétrica do extrato de saturação mostrou valores inferiores aos da salinidade limiar para a cultura do arroz $\left(3,3 \mathrm{dS} \mathrm{m}^{-1}\right)$, em torno de $1,5 \mathrm{dS} \mathrm{m}^{-1}$ para o solo do tratamento com vinhaça, de $3 \mathrm{dS} \mathrm{m}^{-1}$ para o solo do tratamento com gesso e na profundidade de $20-40 \mathrm{~cm}$, valores em torno de $2 \mathrm{dS} \mathrm{m}^{-1}$ para tratamento testemunha e $2,6 \mathrm{dS} \mathrm{m}^{-1}$ para o gesso. Nos solos dos tratamentos com vinhaça e testemunha na camada de $0-20$ e $20-40 \mathrm{~cm}$, foram observados os menores valores de CEes entre 1,5 e 2, respectivamente devido, possivelmente, ao efeito combinado da lavagem com vinhaça (Almeida, 1994) e ao aumento da permeabilidade do solo através da ação física das raízes do arroz, facilitando o movimento da água no perfil do solo e, em conseqüência, diminuição da concentração de sais existentes. A ligeira tendência de aumento da salinidade na camada de $40-60 \mathrm{~cm}$ de profundidade foi por certo, em virtude do acúmulo dos sais provenientes das camadas superficiais.

$\mathrm{O}$ pHps mostrou uma ligeira tendência para decréscimo em todos os tratamentos e profundidades estudados, principalmente na camada de $0-20 \mathrm{~cm}$ do solo, onde os valores médios observados foram de 7,4.

\section{Efeitos dos diferentes condicionadores sobre os componentes de produção e rendimento de arroz}

Os resultados da análises de variância (Tabela 1) revelaram efeito significativo a nível de 0,05 de probabilidade dos tratamentos para peso de 100 grãos, e a nível de 0,01 de probabilidade para as variáveis comprimento de panícula, número de ramificações, número de grãos cheios por panícula e densidade da panícula. As demais variáveis, inclusive rendimentos, não foram afetadas pelos tratamentos estudados. $\mathrm{O}$ contraste entre a testemunha $\left(\mathrm{T}_{3}\right)$ e os outros tratamentos $\left(\mathrm{T}_{1}, \mathrm{~T}_{2}, \mathrm{~T}_{4} \mathrm{e} \mathrm{T}_{5}\right)$ foi significativo a nível de 0,01 de probabilidade, para as variáveis comprimento da panícula, número de ramificações por panícula, peso da panícula e, a nível de 0,05 de probabilidade, para as variáveis número de grãos cheios por panícula, densidade da panícula e rendimento.

A comparação das médias dos tratamentos pelo teste de Tukey, a nível de 0,05 de probabilidade, mostra que o tratamento com esterco de curral, para o comprimento de panícula, diferiu significativamente da testemunha, em média $36,4 \%$ maior que a testemunha. Observa-se, também, que os melhores resultados foram obtidos com os tratamentos esterco de curral e gesso para as variáveis, número de ramificações e peso de panículas. Em relação à variável número de ramificações por panícula, esses tratamentos superam, em média, a testemunha, em $27,6 \%$, enquanto, para a variável peso da panícula, os tratamentos com esterco e com gesso foram $90,2 \%$ e $141,3 \%$, superiores à testemunha, respectivamente. Confrontando-se as médias, o tratamento com esterco de curral superou todos os tratamentos, em todas as variáveis, ficando em segundo lugar o tratamento com gesso. Para a variável densidade da panícula as médias dos tratamentos com gesso, com esterco e com casca de arroz, não diferiram significativamente, porém o esterco superou a

Tabela 1. Médias* observadas de comprimento de panículas $(\mathrm{CP})$, número de panículas $(\mathrm{NP})$, número de ramificações por panícula (NR), peso de panícula (PP), número de grãos por panícula(NG), densidade de panícula (DP), peso de 100 grãos $\left(\mathrm{P}_{100}\right)$ e rendimentos $(\mathrm{R})$

\begin{tabular}{|c|c|c|c|c|c|c|c|c|}
\hline \multirow[b]{2}{*}{ Tratamentos } & \multicolumn{8}{|c|}{ Variáveis Analisadas } \\
\hline & $\begin{array}{l}\mathrm{CP} \\
(\mathrm{cm})\end{array}$ & $\begin{array}{c}\mathrm{NP} \\
\text { (unid.) }\end{array}$ & $\begin{array}{c}\text { NR } \\
\text { (unid.) }\end{array}$ & $\begin{array}{l}\text { PP } \\
\text { (g) }\end{array}$ & $\begin{array}{c}\mathrm{NG} \\
\text { (unid.) }\end{array}$ & DP & $\begin{array}{l}\text { P100 } \\
\text { (g) }\end{array}$ & $\begin{array}{c}\mathrm{R} \\
\left(\mathrm{Mg} \mathrm{ha}^{-1}\right)\end{array}$ \\
\hline$\overline{T_{1}-(G e s s o)}$ & $18,20 \mathrm{ab}$ & $77,8 \mathrm{a}$ & $8,15 \mathrm{a}$ & $1,75 \mathrm{a}$ & $72,45 \mathrm{ab}$ & $3,99 a b$ & $2,28 \mathrm{ab}$ & $6,781 \mathrm{a}$ \\
\hline $\mathrm{T}_{3}-$ (Testemunha) & $14,08 \mathrm{~b}$ & $45,8 \mathrm{a}$ & $5,83 \mathrm{~b}$ & $0,92 \mathrm{a}$ & $41,83 \mathrm{~b}$ & $2,85 \mathrm{~b}$ & $1,93 \mathrm{~b}$ & $3,375 \mathrm{a}$ \\
\hline $\mathrm{T}_{4}-($ Vinhaça $)$ & $16,14 \mathrm{ab}$ & $76,2 \mathrm{a}$ & $6,80 \mathrm{ab}$ & $1,23 \mathrm{a}$ & $49,97 \mathrm{~b}$ & $3,01 \mathrm{~b}$ & $2,33 a b$ & $5,656 \mathrm{a}$ \\
\hline $\mathrm{T}_{5}-($ Esterco de curral $)$ & $19,20 \mathrm{a}$ & $90,2 \mathrm{a}$ & $8,31 \mathrm{a}$ & $2,22 \mathrm{a}$ & $85,55 \mathrm{a}$ & 4,46 a & $2,48 \mathrm{a}$ & $8,813 \mathrm{a}$ \\
\hline
\end{tabular}


testemunha em 56,5\%. Os tratamentos não apresentaram diferenças significativas para a variável rendimento de grãos; contudo, pode-se afirmar que, em média, os componentes associados à produção do arroz nos tratamentos em que se aplicaram os produtos, superaram as respectivas variáveis da testemunha.

Comparando-se o tratamento com o gesso com os tratamentos orgânicos (casca de arroz, vinhaça e esterco de curral) não se verificam diferenças significativas, em nenhuma das variáveis estudadas, indicando que o efeito de correção com gesso sobre as variáveis estudadas não difere do efeito dos produtos orgânicos e, portanto, pode-se confirmar que aplicações prévias de gesso e produtos orgânicos, seguidas de lavagem, melhoram a produtividade agrícola, através do abaixamento da CEes, PST e, conseqüentemente, do pH. Resultados semelhantes foram conseguidos por Leite (1990), e Silva (1997). Por outro lado, o efeito médio da vinhaça contra o efeito dos tratamentos com casca de arroz e esterco de curral foi significativo, a nível 0,05 de probabilidade, na variável densidade da panícula. Na comparação das médias com os demais tratamentos, difere apenas de esterco de curral para as variáveis número de grãos cheios por panícula e densidade da panícula, reforçando resultados conseguidos por Silva \& Orlando Filho (1981); Glória \& Orlando Filho (1983) e Almeida (1994) que atestaram o valor da vinhaça como fertilizante, corretivo e condicionador do solo, devido à sua riqueza em matéria orgânica, potássio e micronutrientes. Finalmente, o tratamento casca de arroz contra o tratamento esterco de curral apresentou diferença significativa a nível de 0,01 de probabilidade nas variáveis número de grãos cheios por panícula e densidade da panícula; a comparação de médias pelo teste Tukey indicou diferenças significativas para essas variáveis com o esterco de curral, superando o tratamento com casca de arroz, em $41,5 \%$ e 28,3\%, respectivamente. Apesar de não terem sido detectadas diferenças significativos pelo teste $\mathrm{F}$, entre os diferentes tratamentos, na variável rendimento de grãos. É importante ressaltar que a média da produtividade sob diferentes tratamentos $\left(6,88 \mathrm{Mg} \mathrm{ha}^{-1}\right)$ foi 2 vezes maior que da testemunha, a qual apresentou rendimento de apenas 3,38 $\mathrm{Mg} \mathrm{ha}^{-1}$, assegurando aumento de receitas ao agricultor. A não observância do efeito significante dos tratamentos nos rendimentos foi devido ao alto valor de coeficiente de variação, em virtude da variabilidade espacial do solo.

\section{CONCLUSÕES}

1. No cultivo de arroz sob inundação, a salinidade (CEes), a percentagem de sódio trocável (PST) e o pH do solo tendem a diminuir com o tempo, principalmente na camada superficial $(0-20 \mathrm{~cm})$ independentemente do emprego dos condicionadores químicos ou orgânicos.

2. Com exceção de número de panícula, peso de panícula e rendimento de arroz, os demais componentes de produção foram afetados significativamente pelos tratamentos estudados mostrando produtividade média entre 3,38 e $8,81 \mathrm{Mg} \mathrm{ha}^{-1}$ de arroz.
3. Os menores valores de percentagem de sódio trocável (PST) no solo foram obtidos com o uso do gesso, enquanto os menores valores de salinidade (CEes) no solo foram alcançados com a utilização da vinhaça.

\section{REFERÊNCIAS BIBLIOGRÁFICAS}

ABROL, I.P.; BHUMBLA, D.R. Crop responses to differential gypsum applications in a highly sodic soil and the tolerance of several crops to exchangeable sodium under field conditions. Soil Science, Baltimore, v.127, n.2, p.79-85, 1979.

ALMEIDA, M.T. Torta de filtro e vinhaça como alternativa na recuperação de um solo salino-sódico. Viçosa: UFV, 1994. 52p. Dissertação Mestrado

AZEVEDO, N.C. de. Influência de vários corretivos nas propriedades físico-químicas de um solo salino-sódico e seus efeitos na cultura do arroz (Oryza sativa, $L$ ) irrigado. Campina Grande: UFPB, 1983. 66p. Dissertação Mestrado

CHABRA, R.; ABROL, I.P. Reclaiming effect of rice grown in sodic soils. Soil Science, Baltimore, v.124, p.49-55, 1977.

CHAPMAN, V.J. The salinity problem in general, its importance, and distribution with special reference to natural halophytes. In: POLJAKOFMAYBER, A.; GALE, J. Plants in saline environments. New York: Springer-Verlag, p.6-24, 1975.

CORDEIRO, G.G.;BARRETO, A.N.;GARRI, A.C.R.C. Levantamento das condições de salinidade e sodicidade do projeto de irrigação de São Gonçalo ( $2^{\mathrm{a}}$ parte). Petrolina: EMBRAPA/CPATSA, 1988. 57p.

DNOCS. Departamento Nacional de Obras Contra as Secas. Grupos de Coordenação Executiva das Operações Agrícolas (GOA). Situação em 30/04/1991. Fortaleza, 1991, sp.

DNOCS. Departamento Nacional de Obras Contra as Secas. $2^{\circ}$ Distrito de Engenharia Rural, 1997, sp. Mimeografado.

EMBRAPA - Empresa Brasileira de Pesquisa Agropecuária. Manual de métodos de análise de solo. Rio de Janeiro: EMBRAPA/SNLCS, 1997, 297p.

FAO/UNESCO. Irrigation drainage and salinity: An international sourcebook. Paris: Hutchison, 1973, 510p.

GHEYI, H.R. Caracterização e recuperação dos solos afetados por sais do Perímetro Irrigado de Sumé, PB. Campina Grande: UFPB, 1993, 107p. Tese Concurso Prof. Titular

GHEYI, H.R.; AZEVEDO, N.C. de; BATISTA, M.A.F.; SANTOS, J.G.R. dos. Comparação de métodos na recuperação de solo salino-sódico. Revista Brasileira de Ciência do Solo, Campinas, v.19, p.173-178, 1995.

GLÓRIA, N.A.; ORLANDO FILHO, J. Aplicação da vinhaça como fertilizante. Boletim Técnico. PLANALSUCAR, 1983, $38 \mathrm{p}$.

GOES, E.S. de O. O problema da salinidade e drenagem em projetos de irrigação do Nordeste e ação de pesquisa, com vistas ao seu equacionamento. In: Reunião Sobre Salinidade em Áreas Irrigadas. Fortaleza: SUDENE/DNOCS. 1978, p.1-34,

GUPTA, R.K.; BHUMBIA, D.K; ABROL, I.P. Effect of sodicity $\mathrm{pH}$, organic matter, and calcium carbonate on the dispersion behaviour of soils. Soil Science, Baltimore, v.137, n.4, p.245-251, 1984.

HOLANDA, J.S. de Manejo de solo salino-sódico na região do Baixo Açu-RN. Piracicaba: ESALQ, 1996. 84p. Tese Doutorado 
KOVDA, V.A.; SZABOLCS, I. Modelling of soil salinization and alkalization. Agrokêmia és Talaitan, v.28, 280p., 1979.

LEITE, E.J. Efeitos de diferentes níveis de gesso e matéria orgânica na recuperação de solos com problema de sódio. Campina Grande: UFPB, 1990, 64p. Dissertação Mestrado

McNEAL, B.L.; PEARSON, G.A; BOWER, C.A. Effect of rice culture on the reclamation of sodic soils. Agronomy Journal, Madison. v. 58, n. 2, p.238-40, 1966.

MORAES, J.F.V. Efeitos da inundação do solo. I. Influência sobre o $\mathrm{pH}$, o potencial de oxido-redução e a disponibilidade do fósforo no solo. Pesquisa Agropecuária Brasileira, Série Agronomia. Brasília, v.8, p.93-101, 1973.

OLIVEIRA, J.J.; CHAVES, L.H.G.; QUEIROZ, J.E.; LUNA, J.G. de. Variabilidade espacial de propriedades químicas de um solo salino-sódico. Revista Brasileira de Ciência do Solo, Viçosa, v.23, p.783-789, 1999.

RICHARDS, L.A. Diagnosis and improvement of saline and alkali soils. Washington: United States Salinity Laboratory Staff, 1954. 160p. Agriculture Handbook, 60

RUIZ, H.O.; GHEYI, H.R.; ALMEIDA, M.T.; RIBEIRO, A.C. Torta de filtro e vinhaça na recuperação de um solo salino sódico e no desenvolvimento de arroz irrigado. Revista Brasileira de Ciência do Solo, Viçosa, v.21, p.659-665, 1997.
SANTOS, R. V.; HERNANDEZ, F. F. F. Recuperação dos solos afetados por sais. In: GHEYI, H.R.; QUEIRÓZ, J.E. ; MEDEIROS, J.F. (ed.), Manejo e controle da salinidade na agricultura. Campina Grande: UFPB/SBEA, 1997. p.319-355.

SILVA, Ê.F. de F. e. Avaliação da eficiência de diversos produtos na recuperação de solo salino-sódico e no desenvolvimento e produção da cultura do arroz (Oryza sativa L.). Campina Grande: UFPB, 1997, 70p. Dissertação Mestrado

SILVA, Ê.F. de F. e; BARRETO, A.N.; GHEYI, H.R.; BEZERRA, J.R.C. Caracterização dos problemas de salinidade dos solos da Estação Experimental da Embrapa-Algodão em São Gonçalo, PB. CONGRESSO BRASILEIRODEENGENHARIA AGRÍCOLA, 26, Campina Grande: UFPB/SBEA. Anais... 1997. CD-Rom

SILVA, G.M. de A.; ORLANDO FILHO. Caracterização da composição química dos diferentes tipos de vinhaça no Brasil. Boletim Técnico. PLANALSUCAR, 1981, 22p.

UN - UNITED NATIONS. World population prospects. New York. United Nations, 607p., 1991. Population Studies No. 120.

WHITEMORE, J. Saline and sodic soils. USA, 1975, 7p. Mimeografado 